\title{
Perceptions regarding strategic and structural entry barriers
}

\author{
Clemens H. M. Lutz • Ron G. M. Kemp • \\ S. Gerhard Dijkstra
}

Accepted: 17 November 2008/Published online: 6 January 2009

(C) The Author(s) 2008. This article is published with open access at Springerlink.com

\begin{abstract}
This article uses factor analysis to identify the underlying dimensions of strategic and structural entry barriers. We find that, in the perception of firms, both types of barriers are important and that the effectiveness of strategic barriers depends on attributes of the market structure. Based on the seven generic factors, a conjoint analysis is carried out to identify the most important factors perceived by firms. The conjoint analysis shows that in particular the barriers rooted in three underlying dimensions require attention of market authorities as they may prevent new entrants from entry: capital, access to distribution channels and strategic action. Remarkably, government rules and regulations, product differentiation, research and development $(\mathrm{R} \& \mathrm{D})$ and advertising constitute minor entry problems according to firms.
\end{abstract}

Keywords Barriers to entry - SMEs .

Antitrust policy $\cdot$ Entrepreneurship

JEL Classifications $\quad$ L11 $\cdot$ L26 $\cdot$ L44 $\cdot$ L52

C. H. M. Lutz $(\bowtie) \cdot$ S. Gerhard Dijkstra

University of Groningen, Groningen, The Netherlands

e-mail: c.h.m.lutz@rug.nl

R. G. M. Kemp

Netherlands Competition Authority, Wageningen

University and Research Centre, Wageningen,

The Netherlands

\section{Introduction ${ }^{1}$}

Small firms, and in particular new firms, serve as agents of change (Audretch 2006; Acs and Storey 2004). Entries of new innovative firms foster the dynamics in the economy. Simultaneously, newcomers may have an equilibrating function, as firms will enter the market if profits are above the long-run competitive level. The upshot is that entry contributes to allocative as well as dynamic efficiency in the market (Audretch and Thurik 2001). However, entry barriers can prevent firms from entering the market and hamper the process of allocative and dynamic efficiency. In line with this perspective it is easily understood that barriers to entry constitute an important issue in entrepreneurship and competition policy. In the framework of competition policy market authorities control the behaviour of firms in specific markets and may impose sanctions if market power is abused. A related issue, which may be raised in the framework of entrepreneurship policy, concerns the question of whether entry barriers restrict the activities of potential entrepreneurs in the modern

\footnotetext{
${ }^{1}$ Part of the research was conducted while Gerhard Dijkstra visited the University of California-Santa Barbara. At the moment of writing this article Ron Kemp worked for EIM. These are the views of the authors and need not reflect those of EIM or the Netherlands Competition Authority. We would like to thank all students who participated in the fieldwork and the course "Small Business Economics". Their reports, enthusiasm and critical comments were highly appreciated.
} 
economy. Is this an incidental problem related to specific sectoral characteristics or a more general phenomenon that hampers entrepreneurial activity in the economy at large?

The latter issue is relevant for policy makers, as quite a body of literature shows that there is a positive relationship between entrepreneurial activity and national economic growth in developed countries (Van Stel et al. 2005; Acs and Storey 2004). In The Netherlands, a country neither among the laggards nor among the top dogs of entrepreneurial activity, this resulted in a debate among politicians and policy makers on policies to encourage entrepreneurship. In this debate two reasons have been given to explain the mediocre position of The Netherlands: existing "entry barriers" and/or a deficient "entrepreneurial attitude". The former phenomenon is related to characteristics of the industries or a lack of servicing industries (e.g. access to credit and venture capital), while the latter phenomenon is more related to psychological and cultural factors and alternative opportunities in the labour market. This article aims at investigating the importance of different entry barriers in the Dutch economy. If vigorous barriers are detected they will at least partly account for the somewhat disappointing level of entrepreneurial activity in The Netherlands.

A large body of literature discusses a variety of entry barriers (see e.g. Shepherd 1997; Karakaya and Stahl 1989). Blees et al. (2003) identified 37 barriers to entry on the basis of a comprehensive literature study. As some of these barriers seem to overlap, two questions arise. Firstly, one may question whether all these barriers are important. Secondly, it is interesting to verify whether these barriers are driven by a reduced set of underlying factors. Some research has been done in this respect (Karakaya 2002; Karakaya and Stahl 1989). A major flaw in this work is that it only concerns manufacturing industries (larger firms). Moreover, Karakaya (2002) mainly addresses structural entry barriers and is based on a relatively small number of observations.

Several authors stress the need for empirical evidence on extant barriers to entry (Scherer 1988; Geroski et al. 1990; Geroski 1995; Bunch and Smiley 1992; Karakaya 2002). This article addresses firms' perceptions with regard to entry barriers. Considering the difficulties of carrying out empirical research on strategic entry barriers (Bunch and Smiley 1992), we decided to interview firms and measure their perception regarding the importance of specific entry barriers. As our study is mainly interested in those barriers that prevent potential entrants from entering an industry, perceptions regarding entry barriers are key. Subjective opinions of business owners influence both growth motivation and direct behaviour (Davidsson 1991). Several researchers followed the same line of thought (Bunch and Smiley 1992; Singh et al. 1998; Karakaya 2002; Aidis 2005). However, all these studies focused on a limited subset of entry barriers or a specific group of companies or industries. Some researchers stress the importance of strategic barriers (Scherer 1988; Bunch and Smiley 1992), while others emphasise the role of structural barriers (Bain 1956; Karakaya 2002). In line with this a limited set of predetermined structural and/or strategic barriers were analysed.

For this study it was important to interview a large number of firms, representative for the Dutch economy, and to include all potential barriers identified in the literature study (Blees et al. 2003). Our sample encompasses the services and manufacturing sectors and involves, in line with the size distribution of firms in the economy, mainly small and medium-sized enterprises (SMEs). First we asked the firms to what extent the specific barriers mentioned in the literature occur in their markets of operation. Subsequently, factor analysis was used to identify the latent variables that drive the perceptions of the respondents. The large number of structural and strategic entry barriers included in our survey provides a proper basis to assess the existence of the underlying dimensions. Moreover, it can be verified whether strategic barriers are grouped in new latent variables separated from structural barriers or that structural and strategic barriers are driven by the same latent force. Finally, a conjoint analysis is carried out to assess the importance of these underlying dimensions, i.e. to identify the most (un)attractive market situation and the most vigorous entry barriers (factors). This part of the study shows which entry barriers really affect entry decisions. In a quasiexperimental setting, different profiles of markets, containing different sets of entry barriers, were presented to the firms and they were asked to rank the attractiveness of those markets.

The next section starts with a concise overview of the literature on entry barriers. The concept is defined 
and the method to measure the importance of entry barriers is discussed in Sect. 3. Subsequently the findings are discussed. Section 4 presents the perceptions of firms regarding existing barriers. The underlying factors are identified in Sect. 5, and Sect. 6 discusses the results of the conjoint analysis. Section 7 concludes.

\section{Literature review}

Two traditions can be distinguished in the literature on entry barriers: the industrial organisation perspective (e.g. Bain 1956; Stigler 1968; Von Weizsacker 1980; McAfee et al. 2004) and the strategic management perspective (e.g. Porter 1980, 1985; Singh et al. 1998; Robinson and McDougall 2001).

The first tradition focusses on the industry as the unit of analysis, strives for efficiency and identifies harmful barriers for economic development. Various models show how entry barriers affect the behaviour of firms and the performance of the industry. Basically, two types of barriers are distinguished: structural and strategic barriers to entry. The structural barriers stem from market structure characteristics and are widely discussed in the tradition of industrial organisation. Bain (1956) introduced the concept of "barriers to new competition". This concept is based on the assumption that competition is key to the operation of industries and that any artificial barrier to competition may reduce the efficient allocation of resources in the industry. Bain stressed the importance of structural characteristics that hamper market entry of potential competitors: economies of scale, technological advantages, absolute cost advantages etc. According to Bain the resulting competitive forces would determine the behaviour of firms and market performance. This deterministic approach has been criticised within the discipline of industrial organisation. By the late 1970s these views became known as "the new industrial organisation" (Geroski et al. 1990). They stressed the importance of behaviour as a determinant for market performance and market structure (in the long run). The approach comes close to the tradition of strategic management, as behavioural aspects are considered to be key. However, in line with the tradition of industrial organisation, the unit of analysis is the industry.
The second tradition, strategic management, takes the firm as the unit of analysis and assesses entry barriers as a resource to create competitive advantage for individual firms. This line of thought stresses the importance of strategic barriers. Following the resource-based view (Barney 1991, p. 99), firms are advised to "obtain sustained competitive advantages by implementing strategies that exploit their internal strengths, through responding to environmental opportunities, while neutralising external threats and avoiding internal weaknesses". In other words, firms are encouraged to develop resources that are difficult to copy or to substitute by competitors (Rangone 1999; Dollinger 2003). These so-called strategic resources form the basis for a sustainable competitive advantage. The upshot is that it is in the interest of incumbent firms to develop strategies, for instance creating entry barriers, that reduce the competitive forces in the market.

From a resource-based perspective entry barriers are considered as resources for incumbent firms. Strikingly, from the perspective of industrial organisation, this resource constitutes a potential danger as it may hamper the allocative and dynamic efficiency of the industry. The contradictory assessment of the value of barriers to entry is related to the unit of analysis and the role that competition is expected to play in the two traditions. At the firm level it is indeed important to strive for sustainable competitive advantage and to exploit available barriers.

Porter (1980, pp. 9-13) specifies seven major sources of barriers to entry: economies of scale, product differentiation, capital requirements, switching costs, access to distribution channels, cost disadvantages independent of scale and government policy. Implicitly he uses a broad definition for barriers to entry in order to encompass structural and strategic barriers. He provides a kind of typology of barriers to entry that firms should take into account when their competitive strategy is developed. Porter's specification also shows that structural and strategic barriers are related. The barrier may be rooted in the market structure, but this will encourage firms to react strategically; for example, advertising can be considered as a structural phenomenon in the automobile industry, however, each actor may develop its own advertising strategy (brand) that affects new competitors. This shows that most structural barriers may have a strategic component too. Therefore, the 
purpose of this article is not only to understand the importance of structural and strategic barriers but also to analyse to what extent the barriers are coherent.

The aim of this discussion is not to identify the right tradition. Both approaches may be relevant and the proper choice depends on the problem under study. We recall that the objective of this research is to identify important entry barriers as perceived by firms (Yip 1982; Karakaya and Stahl 1989; Singh et al. 1998; Smiley 1988). The unit of analysis is the firm. It aims at recognising the major constraints that hamper firms in making their entry decision. Therefore, a broad definition of entry barriers, encompassing all relevant associations made by firms, is adopted for this research. A useful definition is found in Besanko et al. (2007, p. 289): "Barriers to entry are those factors that allow incumbent firms to earn positive economic profits, while making it unprofitable for newcomers to enter the industry". Two types of barriers are distinguished. Structural barriers concern natural cost or marketing advantages resulting from market characteristics that are exogenous to the firm in the short and medium term. Strategic barriers result from a firm's behaviour and concern entry-deterring strategies.

With this definition in mind extant literature has been reviewed. Table 1 gives an overview of the types of barriers observed and provides some key references. Some barriers are grouped together as different names are used for similar problems to highlight a specific focus under study; for example "control over strategic resources", "location" and "vertical integration" all concern the general barrier of "securing inputs". Similarly "strategic behaviour differentiation", and "packing the product space" are grouped together. A discussion of the specific properties of each of these entry barriers is beyond the scope of this article. For further details refer to Blees et al. (2003).

\section{Data collection}

As the concepts involved are sometimes difficult to circumscribe in unambiguous questions a pilot study was carried out in November 2004, in which 40 students participated. The students tested the survey and were asked to write about 100 case studies of the companies they interviewed. The case studies allowed us to grasp the functioning of the perceived barriers to entry in the different industries under study and, therefore, have facilitated the interpretation of the results of the questionnaire. Before contacting the sampled respondents, the final questionnaire was pretested by telephone with potential respondents.

A large number (23) of structural and strategic barriers to entry were presented in the questionnaire (Table 1). However, not all the barriers identified in the literature study (Blees et al. 2003) were addressed separately. Time limitations forced us to reduce the number of barriers. The firms were interviewed by telephone; previous experiences had shown us that this should not take more than $15 \mathrm{~min}$. More time would affect willingness to cooperate. Grouping of barriers solved most of this problem. The literature study showed that several barriers evoke similar problems (e.g. brand name and customer loyalty are related to advertising; experience advantages are part of cost advantages; government regulations are related to government licences; know-how is related to level of technology and patents). Moreover, we observed that separation could give respondents the impression that identical issues were raised in different questions, which could frustrate their cooperation. Consequently we decided to group similar barriers as presented in Table 1 .

Only five barriers mentioned by Blees et al. (2003) were excluded from the survey. The pilot study made it clear that we were not successful in formulating a clear question addressing the barrier of "causal ambiguity". The large majority of respondents were SMEs for which the barrier of "divisionalisation" is not relevant. "Costs of operating in foreign markets" and "cultural distance" were less relevant as most firms supplied domestic markets. "Concentration" was not addressed as it operates as a general precondition for the included strategic entry barriers.

Some aspects were covered by two separate questions in order to be able to make a distinction between the importance of structural and behavioural characteristics of the barriers; for example, with regard to advertising we presented two statements: (1) Firms in the market have high expenditures for advertising and promotion (structural); (2) Products are heavily supported by advertisement and promotion in order to make entry to the market less attractive for new competitors (strategic). We claim 
Table 1 Entry barriers derived from the literature survey and addressed in the survey

$\begin{aligned} & \text { Type of } \\ & \text { barrier }\end{aligned}$
Barrier to entry

Structural Access to distribution/selling expenses (13) Porter (1980), Yip (1982), Karakaya and Stahl (1989), Han et al. (2001)

Access to knowledge/skilled labour/patents/ Yip (1982), Harrigan (1983), Karakaya and Stahl (1989), Shepherd (1997) technological change (3)

Advertising (14)

Capital requirements (22)

Spence (1980), Harrigan (1981), Yip (1982), Netter (1983), Schmalensee (1983), Karakaya and Stahl (1989)

Bain (1956), Porter (1980), Harrigan (1981), Yip (1982), Karakaya and Stahl (1989), Shepherd (1997)

Sales volume (23)

Cost disadvantages or experience disadvantages of newcomers (19)

Costs of capital/special risks and uncertainties (18)

Customer switching costs (7)

Differentiation (16)

Yip (1982)

Bain (1956), Scherer (1970), Yip (1982), Karakaya and Stahl (1989), Geroski et al. (1990), Han et al. (2001)

Demsetz (1982), Shepherd (1997)

Porter (1980), Klemperer (1987, 1992), Karakaya and Stahl (1989), Shepherd (1997), Shy (2002)

Bain (1956), Porter (1980), Schmalensee (1982), Karakaya and Stahl (1989), Shepherd (1997), Martin (2002)

Economies of scale (17)

Bain (1956), Dixit (1980), Scherer (1970), Spence (1980), Harrigan (1981), Schmalensee (1981), Yip (1982), Geroski et al. (1990),

Government regulations-licences and policies (12)

Porter (1980), Dixit and Kyle (1985), Karakaya and Stahl (1989), Shepherd (1997)

Financial risk/sunk costs/asset specificity (21)

Strategic Limit pricing (6)

Masking profit/gaps and asymmetric information (8)

Retaliation (4)

Collusion (2)

Excess capacity (15)

Securing input/control over strategic resources/location/vertical integration (1)

Bain (1956), Porter (1980), Baumol et al. (1982), Geroski et al. (1990), Sutton (1991), Shepherd (1997)

Bain (1956), Milgrom and Roberts (1982), Geroski et al. (1990), Bunch and Smiley (1992), Singh et al. (1998)

Milgrom and Roberts (1982), Geroski et al. (1990), Bunch and Smiley (1992)

Scherer (1970), Yip (1982), Karakaya and Stahl (1989), Bunch and Smiley (1992), Gatignon et al. (1997), Shepherd (1997), Thomas (1999)

Singh et al. (1998), Bain (1956)

Spence (1977), Dixit (1980), Harrigan (1983), Lieberman (1987), Bunch and Smiley (1992), Shepherd (1997), Singh et al. (1998)

Scherer (1970), Yip (1982), Karakaya and Stahl (1989), Shepherd (1997), Singh et al. (1998), Cabral (2000)

Strategic behaviour advertising/brand name/ Bunch and Smiley (1992), Singh et al. (1998) loyalty (10)

Strategic behaviour differentiation/packing the product space (20)

Schmalensee (1978), Bunch and Smiley (1992), Shepherd (1997), Cabral (2000)

Strategic behaviour distribution channels (11)

Strategic behaviour knowledge/pre-emptive patents (5)

Strategic behaviour R\&D (9)

Singh et al. (1998)

Bunch and Smiley (1992), Singh et al. (1998)

Harrigan (1981), Yip (1982), Daems and Douma (1985), Bunch and Smiley (1992), Singh et al. (1998)

${ }^{a}$ The numbers in brackets refer to the barriers presented in Table 2

that the listed barriers to entry in Table 1 give an overview of the most important barriers discussed in the extant literature.
Incumbent companies were asked to indicate on a five-point Likert scale to what extent new competitors would encounter the barrier in 
question. ${ }^{2}$ Ideally the survey should have addressed new and potential competitors with feasible business plans. ${ }^{3}$ It could be argued that perceptions of incumbents may show some bias as these firms have surmounted existing barriers, i.e. knowing how to solve a problem makes the problem trivial. Put differently, past experiences influence mental models and these may differ between incumbents and new competitors. ${ }^{4}$ However, potential newcomers with feasible business plans are difficult to identify for two reasons. Many of these firms are in the inception phase and not yet registered formally and, therefore, difficult to trace. Even more important is that only viable start-ups should be interviewed, as only the opinion of viable firms has to be taken into account; for example, if the bank rejects a deficient business plan on solid grounds and refuses a loan application, the nascent entrepreneur may indicate that capital is indeed a major barrier, while it would have been more appropriate to conclude that the plan was wrong. Therefore we preferred to interview incumbents as they have proven to be viable.

As we are interested in barriers that (potential) entrants may face and not the behaviour of the specific incumbents per se, the questions were directed at practices in the market rather than the firm's specific behaviour. In general, the incumbents were asked to indicate how important a specific

\footnotetext{
2 The reply options were: not at all, nearly not, somewhat, to a large extent, to a very large extent (or alternatively: strongly disagree, disagree, not agree/not disagree, agree, strongly agree).

${ }^{3}$ Even the group of new and potential competitors can be considered as too broad. For the research, information from the "marginal entrant" is needed. This marginal firm is indeed difficult to identify. We note that the marginal firm is not necessarily the same as a nascent entrepreneur as new competitors may concern existing firms.

${ }^{4}$ One of the reviewers proposed to take into account firm age and other variables that may influence respondents' perceptions, to detect potential biases. This is indeed a challenging idea and certainly a topic for further research. Cognitive approaches may be helpful in this respect. Regrettably, information about these specific variables has not been part of our survey. Moreover, only a few empirical research studies are available (Delmar 2006). We recall that the objective of this article is not to explain perceptions, but to identify the different entry barriers perceived by firms operating in the Dutch economy and how these may affect entry decisions. Moreover, new competitors may concern existing firms in related markets and starters may have had working experience in incumbent firms.
}

barrier is if a comparable company (of the same size) wants to enter the major product market in which the incumbent is operational. As barriers to entry are related to product markets and most firms manage multiproduct operations, we explicitly referred to the most important product market. The advantage of this format for the question is that all companies have experience with the market and, therefore, are able to value the importance of the specific barrier.

In total 3,562 firms were contacted for the telephone survey. ${ }^{5}$ This resulted in 1,074 completed responses: 663 micro enterprises, 303 small enterprises and 186 medium and large enterprises (18 unknown) distributed quite equally over the sectors. ${ }^{6}$ This signifies a response rate of $30 \%$. Of the contacted firms, 33\% refused to cooperate. Another $24 \%$ of the contacted firms could not be reached because of an answering machine, get no answer, number engaged or more than six attempts with no response. Finally, with $13 \%$ of the contacted firms an appointment was made but did not result in a completed questionnaire because the targeted sample was reached. Another 96 respondents were added, as they were interviewed by our students in the pilot phase, using the same question format for the barriers under study. ${ }^{7}$ In total the sample consists of 1,170 Dutch firms distributed over six industries, i.e. furniture, employment agencies, chemical industry, ICT, food (production of bread) and retail (clothing and shoes). ${ }^{8}$

\footnotetext{
5 A telephone survey was preferred for the following reasons: generally these surveys have a higher response rate and result in a more complete data set (fewer missing values), less time is needed for data collection and more control over the stratified sample is possible during the data collection process.

${ }^{6}$ In total 209 firms belonged to the furniture sector, 204 to the employment agency sector, 174 to the chemical industry, 215 to the information and communications technology (ICT) sector, 157 to the food sector and 193 to the retail sector.

${ }^{7}$ It could be argued that students are not very experienced interviewers. However, we believe that their results are reliable as this group was intensively supervised by the researchers. For most barriers, no significant differences were found between the data from the telephonic interview and the students' interviews. Therefore, pooling the data is admissible.

8 The standaard bedrijfsindeling (SBI, standard industrial classification) code of the Netherlands Chamber of Commerce for the industries were 361 (furniture), 74,501 (employment agencies), 24 excluding 241 (chemical industry), 721 and 722 (ICT), 158 (food, production of bread) and 5,242 and 5,243 (retail, clothing and shoes).
} 
Table 2 Perceived barriers to entry

\begin{tabular}{|c|c|c|c|}
\hline Barrier to entry & Mean score* & "Sectoral" differences** & "Scale" differences*** \\
\hline 1. Securing input & 1.73 & $\mathrm{f}, \mathrm{b}>\mathrm{e} ; \mathrm{f}, \mathrm{e}, \mathrm{i}<\mathrm{c}, \mathrm{r} ; \mathrm{c}, \mathrm{b}<\mathrm{r} ; \mathrm{i}<\mathrm{b}$ & Ns \\
\hline 2. Collusion & 1.78 & $\mathrm{f}<\mathrm{e}, \mathrm{b}, \mathrm{r} ; \mathrm{e}>\mathrm{f}, \mathrm{c}, \mathrm{i}, \mathrm{b}, \mathrm{r} ; \mathrm{c}<\mathrm{r}$ & $\mathrm{MIE}>\mathrm{SE}, \mathrm{MLE}$ \\
\hline 3. Knowledge & 1.92 & f,e,i,b,r $<\mathrm{c} ; \mathrm{e}<\mathrm{i}, \mathrm{b}$ & $\mathrm{MIE}<\mathrm{SE}, \mathrm{MLE}$ \\
\hline 4. Retaliation & 2.04 & $\mathrm{f}<\mathrm{e}, \mathrm{c}, \mathrm{b} ; \mathrm{c}, \mathrm{b}>\mathrm{i}$ & MIE $<$ MLE \\
\hline 5. Behaviour knowledge & 2.13 & f,e,i,b,r $<\mathrm{c}$ & Ns \\
\hline 6. Limit pricing & 2.25 & $\mathrm{e}, \mathrm{b}>\mathrm{i}, \mathrm{r}$ & Ns \\
\hline 7. Switching costs & 2.27 & $\mathrm{f}, \mathrm{e}, \mathrm{b}, \mathrm{r}<\mathrm{c}, \mathrm{I}$ & MIE $<$ SE, MLE \\
\hline 8. Masking profit & 2.28 & $\mathrm{f}<\mathrm{e}, \mathrm{b}, \mathrm{r}$ & Ns \\
\hline 9. Behaviour R\&D & 2.32 & $\mathrm{f}, \mathrm{e}, \mathrm{r}<\mathrm{c}, \mathrm{I} ; \mathrm{e}<\mathrm{b} ; \mathrm{c}>\mathrm{i}, \mathrm{b}$ & $\mathrm{MIE}<\mathrm{SE}, \mathrm{MLE}$ \\
\hline 10. Behaviour advertising & 2.39 & $\mathrm{f}, \mathrm{c}, \mathrm{i}<\mathrm{r} ; \mathrm{e}>\mathrm{i}$ & Ns \\
\hline 11. Behaviour distribution channel & 2.42 & $\mathrm{f}<\mathrm{e}, \mathrm{c}, \mathrm{i}, \mathrm{b} ; \mathrm{e}>\mathrm{f}, \mathrm{c}, \mathrm{i}, \mathrm{b}, \mathrm{r}$ & $\operatorname{MIE}<\operatorname{MLE}(p<0.10)$ \\
\hline 12. Government regulation & 2.52 & $\mathrm{f}, \mathrm{e}<\mathrm{c}, \mathrm{b} ; \mathrm{f}, \mathrm{e}, \mathrm{c}, \mathrm{b}>\mathrm{i} ; \mathrm{e}, \mathrm{c}, \mathrm{b}>\mathrm{r}$ & $\mathrm{MIE}<\mathrm{SE}, \mathrm{MLE}$ \\
\hline 13. Distribution & 2.77 & $\mathrm{f}, \mathrm{i}, \mathrm{r}<\mathrm{b} ; \mathrm{c}>\mathrm{r}$ & Ns \\
\hline 14. Advertising & 2.80 & $\mathrm{f}, \mathrm{c}, \mathrm{i}, \mathrm{b}<\mathrm{r} ; \mathrm{e}>\mathrm{i}$ & Ns \\
\hline 15. Excess capacity & 2.87 & $\mathrm{f}, \mathrm{i}, \mathrm{r}<\mathrm{b}$ & MIE, SE $<$ MLE \\
\hline 16. Differentiation & 3.03 & $\mathrm{f}, \mathrm{e}<\mathrm{c}, \mathrm{i}, \mathrm{b}, \mathrm{r}$ & Ns \\
\hline 17. Economies of scale & 3.15 & $\mathrm{f}>\mathrm{e}, \mathrm{i}, \mathrm{r} ; \mathrm{e}, \mathrm{I}, \mathrm{r}<\mathrm{b} ; \mathrm{c}>\mathrm{i}$ & $\mathrm{MIE}<\mathrm{SE}, \mathrm{MLE}$ \\
\hline 18. Costs of capital & 3.24 & $\mathrm{f}, \mathrm{c}, \mathrm{i}<\mathrm{b}, \mathrm{r} ; \mathrm{e}<\mathrm{b}$ & Ns \\
\hline 19. Cost disadvantage & 3.25 & $\mathrm{f}, \mathrm{e}, \mathrm{c}, \mathrm{i}<\mathrm{b} ; \mathrm{e}<\mathrm{c}, \mathrm{r} ; \mathrm{i}<\mathrm{r}$ & Ns \\
\hline 20. Behaviour differentiation & 3.33 & $\mathrm{e}, \mathrm{i}<\mathrm{b}$ & MIE $<$ MLE \\
\hline 21. Financial risk & 3.50 & $\mathrm{f}, \mathrm{e}, \mathrm{i}<\mathrm{b}, \mathrm{r} ; \mathrm{c}<\mathrm{r} ; \mathrm{c}>\mathrm{i}$ & Ns \\
\hline 22. Capital & 3.53 & $\mathrm{f}, \mathrm{c}, \mathrm{b}, \mathrm{r}>\mathrm{i} ; \mathrm{f}, \mathrm{e}, \mathrm{c}<\mathrm{b} ; \mathrm{e}<\mathrm{r}$ & Ns \\
\hline 23. Sales volume & 3.84 & $\mathrm{e}<\mathrm{b}(p<0.10)$ & $\operatorname{MIE}<\operatorname{MLE}(p<0.10)$ \\
\hline Mean score all barriers & 2.52 & $\mathrm{f}<\mathrm{e}, \mathrm{c}, \mathrm{b}, \mathrm{r} ; \mathrm{i}<\mathrm{c}, \mathrm{b}, \mathrm{r}$ & MIE $<$ MLE \\
\hline
\end{tabular}

* Reply options were: $1=$ not at all, $2=$ nearly not, $3=$ somewhat, $4=$ to a large extent, $5=$ to a very large extent

** Significant $p<0.05$ unless otherwise indicated. $\mathrm{f}=$ furniture, $\mathrm{e}=$ employment agencies, $\mathrm{c}=$ chemical industries, $\mathrm{i}=\mathrm{ict}$, $\mathrm{b}=$ food, $\mathrm{r}=$ retail

*** Significant at $p<0.05$ unless otherwise indicated. MIE $=$ micro enterprises, $\mathrm{SE}=$ small enterprises, MLE $=$ medium and large enterprises, Ns $=$ not significant

The aim was to collect data for approximately 175-200 firms per sector divided over three size categories: micro enterprises ( $<10$ employees), small enterprises (10 to $<50$ employees) and medium and large enterprises (50+ employees). Per size category, the firms were selected at random from the Direct Marketing CD database of MarketSelect. ${ }^{9}$ In some sectors all existing firms were contacted in the size category of $50+$ employees, because of the limited number of larger firms in those sectors. Most observations are in the class of $<10$ employees, or

\footnotetext{
9 The database is based on information on business registrations by the Netherlands Chamber of Commerce, address information by TNT Post and checks by MarketSelect.
}

micro firms. In the retail sector, we only have five observations of firms with 50 employees or more. As the sample was drawn from a database including subsidiaries and branches of larger firms, and responses were provided by local managers, the questions concern employment figures of the selected subsidiary. About $40 \%$ of the interviewed establishments are related to a larger company.

The MarketSelect database was used to test for nonresponse bias. Smaller firms were more willing to participate in the research than large firms. This holds for the total sample as well as for the sectors furniture, employment agencies, chemical industry and ICT. No significant differences related to size were found for the food industry and retail. In the 
food industry, firms were less willing to participate in the research compared with the other sectors, probably because of the Christmas rush.

For the final part of this study, the conjoint analysis, another group of firms $(n=119)$ was interviewed by students in November 2006. In the framework of their studies they carried out a case study assignment on the entry barriers these firms were facing. The conjoint analysis was part of the assignment. The selected firms were SMEs (fewer than 100 employees) in the manufacturing (somewhat underrepresented) and services industries (somewhat overrepresented) in the northern region of the Netherlands. We expect that sampling bias is unlikely as sectoral differences are limited and do not affect the ranking of the importance of the different entry barriers (Sect. 4). Moreover, the conjoint analysis concerns a hypothetical market situation (Sect. 6) which excludes sectoral and regional differences.

Literature shows that attitudes, past experiences and competencies affect mental models and therefore may influence the results of the conjoint analysis (Davidsson 1991; Boyd and Vozikis 1994). Reviewing this literature, Delmar (2006, p. 174) concludes that "there have been several conceptual papers advocating cognitive theories, but little empirical research has actually been carried out where different models have been systematically tested". Taking into account the complexity of this matter and that the objective of this article is to verify whether the important barriers in the firms' markets of operation (Table 3) may affect entry decisions (Table 4), we conclude that it is beyond the scope of this research to analyse the relationship between perceptions, attitudes, competencies and past experiences. For the presented results of the conjoint analysis this means that they should be interpreted with some reservation as the sample size is small and control for potential sampling bias is incomplete due to a lack of insight into how perceptions are formed.

\section{Findings: perceived entry barriers in the firms' markets}

In Table 2 the perceived importance of the barriers in the markets under study is presented. Overall, securing input for newcomers, collusion among incumbents, access to knowledge for newcomers, retaliation and knowledge protection by incumbents are the least important barriers. According to the interviewed firms most barriers concern unimportant constraints (value lower than 3 ). ${ }^{10}$ The mean score is 2.5 and implies that on average barriers are not perceived as major constraints: "nearly not" or "somewhat" important. However, some barriers seem to play an important role: the required sales volume for entrants, the needed capital and financial risk for newcomers, behaviour with regard to product differentiation by incumbents, cost disadvantage and costs of capital for newcomers.

The importance of half of the barriers under study did not differ significantly between firms of different size. However, for collusion, knowledge, retaliation, switching costs, strategic behaviour related to R\&D, government policy, excess capacity, economies of scale and strategic behaviour related to differentiation some significant differences are observed between firms of different size (5\% level). The excess capacity barrier is more important in the perception of medium-sized and large firms than for micro and small firms. In a market with excess capacity, it will be more difficult for a relatively large firm to enter because it brings considerable extra capacity to the market. This finding confirms the difference that is made in theory between small-scale and large-scale entry. The barrier related to collusion is somewhat higher for micro firms. However, we note that even the average value of micro firms for the importance of this barrier is low. The scores for all other barriers with significant differences between firm size classes show that micro firms gave lower values than medium and large firms. Even the value given by micro enterprises to the most important barrier (sales volume) is lower than the value given by medium and large firms. The upshot is that, on average, micro firms perceive lower barriers to entry than mediumsized and large firms. This is a surprising result as many researchers expect the opposite (see Blees et al. 2003).

In general the ranking of the importance of specific barriers to entry is coherent between the sectors: securing input and collusion are of minor importance for all but two sectors (retail and employment agencies), while sales volume and capital are most

\footnotetext{
${ }^{10}$ The scores have the same range as previous research, see e.g. Smiley (1988) and Karakaya (2002).
} 
important for all sectors. Overall, the firms valued only a few barriers as important constraints. Capital and sales volume are key issues in all sectors. However, some significant sectoral differences are observed. For instance, securing input is relatively important in retailing and knowledge is relatively important in the chemical industry (Kemp and Lutz 2006). The ICT and furniture industry are sectors with relatively low barriers; the chemical, retail and food industry show relatively high values for the barriers under consideration.

\section{The underlying dimensions of barriers to entry}

The covariance matrix shows that perceptions regarding several of the entry barriers are strongly coherent. Therefore a factor analysis was carried out in order to verify whether some underlying latent variables drive the firms' perceptions. The covariance matrix is nonsingular. Based on the correlation matrix we obtain a Kaiser-Meyer-Olkin (KMO) value of 0.840, and Bartlett's test of sphericity is significant at the 0.0005 level. This implies that the perceptions with regard to each of the barriers can be explained by the other barriers.

The determination of the number of factors is not a straightforward process. According to the method used, five, six or seven factors can be distinguished. ${ }^{11}$ We applied Kaiser's rule stating that each factor should explain at least the average variance. This method may lead to an overestimation of the number of factors (Horn 1965). The consequences of overestimation are preferred to the consequences of a

\footnotetext{
$\overline{11}$ Interestingly, the results are quite robust if the number of factors is reduced to six or five. The first five factors are identified in all these models and in general the same variables receive high factor loadings. The advertising barriers are identified as a separate factor in the six-factor model while these variables receive a relatively high factor loading in the capital and strategic action factor if a five-factor model is estimated. In the five- and six-factor models, government regulation receives a high loading in the factor of access to distribution channels. The advantage of the seven-factor model is that it leads to an unambiguous interpretation. It allows for a distinctive role of advertising. The same applies for government regulation. In the other models it would be difficult to interpret meaning in connection with access to distribution channels.
}

method that fails to identify separate factors (Fava and Velicer 1996). ${ }^{12}$

The factor analysis identifies seven factors that constitute the underlying system and drive the perceptions with regard to entry barriers: capital, strategic action, $\mathrm{R} \& \mathrm{D}$, product differentiation, distribution, advertising and government regulations (Table 3). In total $55 \%$ of the total variation is explained by these factors. Nearly all entry barriers are strongly represented by one of the factors as, in general, the factor loadings are relatively high for only one of the identified factors $(>0.60)$. Except for switching costs the attribution of a barrier to a specific factor is straightforward. Switching costs were positively coherent with $R \& D$ and negatively with advertising. This indicates that $R \& D$ is more attractive if switching costs exist. Alternatively, advertising is less necessary if switching costs prevail or cannot be created through brand loyalty programs.

Some barriers are weakly represented in several factors: securing input, economies of scale and sales volume. In particular sales volume and economies of scale require attention as the values given to these barriers were high. It may be argued that these high values result from the medium factor loadings (between 0.21 and 0.48 ) on several factors (capital, distribution, advertising, strategic action and product differentiation). McAfee et al. (2004) called these types of barriers "ancillary barriers". They do not constitute barriers in themselves, but reinforce other barriers to entry if they are present. Their paper discusses the example of economies of scale that reinforces the entry-deterrent effects of brand loyalty and risk. Our research results show that the values given to these specific entry barriers were generally lower than the importance given to sales volume. This indicates that sales volume is perceived as the most important barrier by firms as it reflects the cumulative effect of the identified factors. This also shows that, even if the scores for the individual entry barriers are quite acceptable (less than 3), the

\footnotetext{
$\overline{12}$ First a factor analysis was carried out on two-thirds of the sample. The results were compared with a one-third holdout sample. As the results were similar we ran a factor analysis on the entire dataset.
} 
Table 3 Seven factors representing the underlying dimensions ${ }^{\mathrm{a}}$

\begin{tabular}{|c|c|c|c|c|c|c|c|c|}
\hline \multicolumn{2}{|c|}{ Barrier } & \multirow{2}{*}{$\begin{array}{l}\begin{array}{l}\text { Factor 1: } \\
\text { capital }\end{array} \\
\mathbf{1 . 0 1 2}\end{array}$} & \multirow{2}{*}{$\begin{array}{l}\text { Factor 2: } \\
\text { strategic action } \\
0.197\end{array}$} & \multirow{2}{*}{$\begin{array}{l}\text { Factor 3: } \\
\text { R\&D } \\
0.077\end{array}$} & \multirow{2}{*}{$\begin{array}{l}\text { Factor 4: product } \\
\text { differentiation } \\
-0.023\end{array}$} & \multirow{2}{*}{$\begin{array}{l}\text { Factor 5: } \\
\text { distribution } \\
0.061\end{array}$} & \multirow{2}{*}{$\begin{array}{l}\text { Factor 6: } \\
\text { advertising } \\
0.096\end{array}$} & \multirow{2}{*}{$\begin{array}{l}\begin{array}{l}\text { Factor } 7: \\
\text { government } \\
\text { regulation }\end{array} \\
-0.025\end{array}$} \\
\hline 1 & Costs of capital & & & & & & & \\
\hline & Capital & 0.918 & -0.181 & 0.124 & 0.012 & 0.103 & 0.195 & 0.153 \\
\hline & Financial risk & 0.853 & 0.037 & 0.158 & 0.154 & 0.051 & 0.185 & 0.115 \\
\hline & Cost disadvantage & 0.758 & 0.191 & 0.068 & 0.138 & 0.038 & -0.058 & 0.078 \\
\hline \multirow[t]{6}{*}{2} & Limit pricing & 0.209 & 0.967 & -0.053 & 0.093 & 0.072 & -0.228 & 0.042 \\
\hline & $\begin{array}{l}\text { Behaviour } \\
\text { distribution } \\
\text { channel }\end{array}$ & -0.046 & 0.797 & 0.243 & -0.009 & 0.532 & 0.372 & 0.043 \\
\hline & Retaliation & -0.006 & 0.712 & 0.213 & 0.185 & 0.014 & 0.193 & 0.347 \\
\hline & Excess capacity & 0.349 & 0.708 & -0.039 & 0.517 & -0.117 & -0.150 & 0.106 \\
\hline & Masking profit & 0.060 & 0.707 & 0.203 & 0.058 & 0.168 & 0.107 & -0.109 \\
\hline & Collusion & 0.032 & 0.654 & 0.125 & -0.130 & -0.019 & 0.251 & -0.017 \\
\hline \multirow[t]{4}{*}{3} & Knowledge & 0.081 & -0.010 & 0.934 & 0.126 & 0.070 & 0.015 & 0.158 \\
\hline & Behaviour R\&D & 0.063 & 0.118 & 0.910 & 0.226 & 0.090 & -0.248 & 0.107 \\
\hline & $\begin{array}{l}\text { Behaviour } \\
\text { knowledge }\end{array}$ & 0.053 & 0.205 & 0.900 & -0.014 & -0.017 & 0.219 & 0.124 \\
\hline & Switching costs & 0.194 & 0.280 & 0.699 & 0.214 & -0.028 & -0.634 & -0.266 \\
\hline \multirow[t]{2}{*}{4} & Differentiation & 0.078 & -0.026 & 0.301 & 0.960 & 0.075 & 0.218 & 0.017 \\
\hline & $\begin{array}{l}\text { Behaviour } \\
\text { differentiation }\end{array}$ & 0.156 & 0.140 & 0.045 & 0.950 & 0.220 & 0.037 & 0.060 \\
\hline 5 & Distribution & 0.113 & 0.078 & 0.155 & 0.130 & 1.255 & 0.044 & 0.141 \\
\hline \multirow[t]{2}{*}{6} & Advertising & 0.306 & 0.259 & -0.019 & 0.174 & -0.027 & 0.703 & -0.108 \\
\hline & $\begin{array}{l}\text { Behaviour } \\
\text { advertising }\end{array}$ & 0.255 & 0.419 & 0.134 & 0.354 & 0.009 & 0.646 & -0.035 \\
\hline \multirow[t]{4}{*}{7} & $\begin{array}{l}\text { Government } \\
\text { regulations }\end{array}$ & 0.348 & 0.151 & 0.278 & 0.088 & 0.139 & -0.098 & 1.305 \\
\hline & Securing input & 0.293 & 0.206 & 0.432 & -0.061 & 0.088 & 0.202 & -0.122 \\
\hline & Economies of scale & 0.446 & 0.266 & 0.011 & 0.252 & 0.479 & -0.326 & -0.061 \\
\hline & Sales volume & 0.323 & 0.096 & -0.032 & 0.153 & 0.316 & -0.037 & -0.006 \\
\hline
\end{tabular}

${ }^{a}$ Extraction method: principal component analysis. Rotation method: varimax with Kaiser normalisation

First a factor analysis was carried out on two-thirds of the sample. The results were compared with a one-third holdout sample. As the results were similar we ran a factor analysis on the entire dataset. Bold indicates the factor loadings given for the entry barriers included in the factors (factor loadings $>0.60$ )

combined effect of the factors can be much stronger: "Because they can interact with and magnify each other's effects, what might seem like a fairly innocuous circumstance when regarded individually may be more problematic when the presence of other barriers is taken into account" (OECD 2005, p. 19).

The factors government regulation, capital and distribution can be considered as structural barriers. Three factors encompass strategic and structural elements: R\&D, product differentiation and advertising. The latter result shows that strategic and structural effects are coherent. Although the literature stresses the differences between the two types of barriers, practice shows that the effectiveness of strategic entry barriers is dependent on characteristics of the market structure. Specific structural attributes do not drive strategic entry barriers but are a necessary condition for the effectiveness of strategic barriers; for example, in a market for bulk products a product differentiation strategy is 
ineffective, but in a market with differentiated products a product differentiation strategy is key. The factor of strategic action seems to resemble a pure strategic barrier. However, even for this factor it is clear that a strategy of excess capacity and retaliation can be effective only if the number of competitors is limited. This implies that the effectiveness of strategic barriers depends on attributes of the market structure.

Remarkably, despite the differences in research setup, some similarities exist with the research results of Karakaya. In these studies three factors in consumer goods markets (Karakaya and Stahl 1989) and four factors in industrial markets (Karakaya 2002) were identified: firm-specific advantages, product differentiation, financial requirements or costs of market entry and profit expectation of entering firms. The last factor does not particularly concern an entry barrier, but rather a set of indicators for market attractiveness. The first three factors identified by Karakaya are coherent with the factors identified in our study. A major new insight is the difference in the number of underlying dimensions and the identification of factors such as strategic behaviour, R\&D and government regulations. Having identified the underlying dimensions the question arises of how important these different dimensions really are.

\section{Conjoint analysis to identify the most important entry barriers}

As all barriers are generally present to a smaller or larger degree, it is preferred to measure the importance of a specific barrier in combination with the existence of other barriers. A full-profile conjoint analysis was conducted to test the underlying dependence of the entry barriers. Conjoint analysis is commonly used in marketing research to analyse consumer tradeoffs (Wittink and Cattin 1989). During the last decade conjoint analysis has also been used as an analytical tool in managerial decision making (see e.g. Priem 1992; Shepherd 1999; Shepherd and Zacharakis 2000; McDermoll et al. 2004). In full-profile conjoint analysis a set of hypothetical alternatives is constructed, and each alternative or profile stands for a combination of the distinguished attributes. Conjoint analysis is able to derive the importance of each attribute (relative weights) from the choices made, between the different profiles, by the respondents. The profiles are constructed in a systematic way, using a decomposition approach (Churchill 1999).

In our conjoint analysis, respondents were asked to rank $^{13}$ ten profiles (eight profiles and two holdout profiles). As the number of 23 barriers (Sect. 4) is too large for respondents to fully evaluate the differences between the profiles, we used the seven identified underlying dimensions (Sect. 5) in the conjoint analysis; for example, one of the profiles consisted of the following market characteristics: (1) high expenditures on advertisement are necessary, (2) it is difficult to access distribution channels or customers, (3) much capital is needed for entry, (4) few government entry regulations apply, (5) hardly any product differentiation exists, (6) high expenditures for $R \& D$ are needed, (7) incumbents hardly react to entry. The barriers could have the value of high/ difficult/strong/much versus low/easy/hardly/few (see also Karakaya and Stahl 1989).

For the construction of the profiles we used the orthogonal factorial design module of SPSS to reduce the number of attribute combinations and to accommodate multicollinearity. Given the seven market characteristics, with two levels each, ten profiles suffice for reliable estimates. To overcome potential ordering effects on the attributes, the order of the characteristics was randomly designed over the participants.

The conjoint analysis for the managers was introduced as if a friend was asking for advice to start a new business and the context of the business, a market profile, was characterised by the seven barriers. These barriers were defined and described in the introduction. We used the underlying items of each factor to clarify the barrier. In analysing the results, we estimated the effects on the aggregate level using SPSS. In Table 4 the relative importance of the seven barriers is presented. ${ }^{14}$ For calculating

\footnotetext{
$\overline{13}$ In the studies of Shepherd a rating task was used: all profiles were evaluated one at a time. We used a ranking task: all profiles were ranked at the same time. This has some consequences for the way the conjoint analysis is administered and analysed.

14 No weighting criteria have been applied as all observations concern equal hypothetical situations.
} 
Table 4 The importance of the underlying dimensions (relative weights)

\begin{tabular}{ll}
\hline & Manager/owner $(n=119)$ \\
\hline Capital & 28.2 \\
Distribution & 21.8 \\
Strategic action & 18.8 \\
R\&D & 14.1 \\
Advertising & 10.0 \\
Government regulation & 6.4 \\
Product differentiation & 0.6 \\
\hline
\end{tabular}

the relative importance the following formula is used:

Importance $_{i}=100 \frac{\text { Range }_{i}}{\sum_{i=1}^{p} \text { Range }_{i}}$

where Range is the difference between the highest and the lowest utility for factor $i$. The holdout profiles were perfectly predicted.

The results of the conjoint analysis identify the most attractive market profiles and allow us to deduce the most vigorous entry barriers that influence entry decisions. Managers find capital by far the most important barrier, followed by access to distribution and strategic action of incumbents. Product differentiation is given the lowest value.

The results of Tables 2 and 4 seem to be somewhat contradictory. Both tables confirm the importance of capital. However the role of strategic action and distribution is given more importance in Table 4 than in Table 2, while $\mathrm{R} \& \mathrm{D}$, government regulation, advertising and product differentiation receive lower scores. It is important to recall that the results in Table 2 are based on the question "is the specific barrier important in your market?", whereas the results in Table 4 are based on the question "how attractive is the market profile in which the following set of market barriers exist?". The differences between these questions explain the differences in results. Table 2 shows the importance of a specific barrier in the market in which the firm operates. The scores indicate that in most markets under study the importance of these barriers is not worrisome (generally average values below 3 ). In particular financial issues seem to play an important role in existing markets. This finding receives extra significance in
Table 4, which shows that manager/owners weigh this factor most in markets where these barriers are operational. Table 4 also shows that, although strategic action and distribution barriers are not really hampering the firms in their markets of operation, they would be perceived as a serious barrier to entry if they were to exist. At the same time the results show that, even if government regulation and product differentiation would constrain the market operations, these barriers would barely influence entry decisions of newcomers to such a market. This result concerning government regulations is not in line with Djankov et al. (2002), but supports the findings presented by Van Stel et al. (2006, 2007) that administrative considerations do not seem to influence nascent or young business formation. Also the conclusions drawn by Capelleras et al. (2008) point in the same direction.

\section{Conclusions}

The literature review showed a need for empirical evidence about entry barriers. Although many theoretical models exist, little empirical research has actually been carried out. The results of this article shed some empirical light on the phenomenon of entry barriers and in particular on the perception of firms regarding the importance of different structural and strategic barriers. In the analysis two different aspects are given attention: which entry barriers do play a role in the markets in which the firms operate, and which barriers would affect entry decisions most.

Barriers related to capital are most important in the perception of existing firms. Fortunately, most barriers in Table 2 seem to play only a minor role as the average scores for their importance are rather low ("nearly not" or "somewhat" important). However, specific barriers may reinforce each other and result in a more substantial effect if their interaction is taken into account; for example, the creation of sufficient sales volume is generally perceived as the most important entry barrier. The factor analysis shows that this results from the interaction of barriers, mainly related to capital and distribution.

In the debate on entry barriers some researchers stress the importance of one of the two strands of barriers. Table 4 provides some support for the structuralists (capital is a structural and important 
barrier), but also for the behaviourists (strategic action does matter). The factor analysis allowed us to identify the seven underlying dimensions that drive the system: capital, strategic action, $R \& D$, product differentiation, distribution, advertising and government regulation. A striking result is that some structural and strategic barriers are coherent: some barriers are rooted in the market structure but this seems to encourage firms to react strategically. The importance of knowledge, patenting and switching costs may serve as an interesting example. Advertising and product differentiation provide similar examples where structural barriers induce strategic actions. We conclude that the effectiveness of strategic barriers depends on attributes of market structure.

Based on the seven generic factors, a conjoint analysis was carried out to identify the most important factors affecting entry decisions. The analysis shows that in general the barriers rooted in three underlying dimensions require attention of market authorities as they may prevent new entrants from entry to specific markets: capital, access to distribution channels and strategic action. Government regulations, product differentiation, R\&D and advertising constitute a minor entry problem according to the firms.

The results confirm that several barriers may influence entry decisions. Consequently, entry barriers can reduce the amount of entrepreneurial activity and potential competition. Although the data indicate that this is not a general phenomenon in the Dutch economy at large (Table 2) it may constrain competitive forces in specific markets. Some authors claim that in the entrepreneurial economy less attention should be paid to regulation (Audretch and Thurik 2001). They observe a tradeoff between stimulation versus regulation. Our findings rather suggest that both policies complement each other: stimulation and regulation are instruments of policies that encourage entrepreneurial activity. In particular strategic action and distribution policies in specific sectors may require attention of market authorities.

We conclude with some limitations of the study. Firstly, in Sect. 3 we discussed that only managers of existing companies were interviewed. These managers have experience in the market and, therefore, their perceptions regarding entry barriers may differ from, for example, those of nascent entrepreneurs. Further study is needed to analyse these potential differences. Secondly, more empirical research is needed to analyse how perceptions regarding entry barriers are determined by past experiences, attitudes and competencies. Thirdly the study is limited to a single country and relies on data from a selected number of industries. Extension of the research to other countries would help to determine how far these results can be generalised. Finally, we only identified the perceived barriers. Studies that relate the perceived barriers to actual entry are needed (e.g. Van Stel et al. 2006, 2007). This would help to shed light on the extent to which the identified barriers really influence the entry process.

Open Access This article is distributed under the terms of the Creative Commons Attribution Noncommercial License which permits any noncommercial use, distribution, and reproduction in any medium, provided the original author(s) and source are credited.

\section{References}

Acs, Z. J., \& Storey, D. J. (2004). Introduction: Entrepreneurship and economic development. Regional Studies, $38,871-877$.

Aidis, R. (2005). Institutional barriers to small- and mediumsized enterprise operations in transition countries. Small Business Economics, 25, 305-318.

Audretch, D. B. (2006). Entrepreneurship, innovation and economic growth. Cheltenham: Edward Elgar.

Audretch, D. B., \& Thurik, R. (2001). What's new about the new economy? Sources of growth in the managed and entrepreneurial economies. Industrial and Corporate Change, 10, 267-315.

Bain, J. S. (1956). Barriers to new competition. Cambridge, MA: Harvard University Press.

Barney, J. B. (1991). Firm resources and sustained competitive advantage. Journal of Management, March, 99-120.

Baumol, W. J., Panzar, J., \& Willig, R. D. (1982). Contestable markets and the theory of industry structure. New York, NY: Harcourt Brace Jovanovich.

Besanko, D., Dranove, D., Shanley, M., \& Schaefer, S. (2007). Economics of strategy. UK: Wiley.

Blees, J., Kemp, R. G. M., Maas, J., \& Mosselman, M. (2003). Barriers to entry. Differences in barriers to entry for SME's and large enterprises. EIM Research Report H200301, The Netherlands.

Boyd, N. C., \& Vozikis, G. S. (1994). The influence of selfefficacy on the development of entrepreneurial intentions and actions. Entrepreneurship: Theory and Practice, 18, 63-78.

Bunch, D. S., \& Smiley, R. (1992). Who deters entry? Evidence on the use of strategic entry deterrents. Review of Economics and Statistics, 74(3), 509-521. 
Cabral, L. M. B. (2000). Introduction to industrial organisation. London: MIT Press.

Capelleras, J.-L., Mole, K. F., Greene, F. J., \& Storey, D. J. (2008). Do more heavily regulated economies have poorer performing new ventures? Evidence from Britain and Spain. Journal of International Business Studies, 39(4), 688-704.

Churchill, G. A. (1999). Marketing research: Methodological foundations. Orlando, FL, USA: Dryden.

Daems, H., \& Douma, S. W. (1985). Concurrentie: Analyse en strategie. Deventer: Kluwer.

Davidsson, P. (1991). Continued entrepreneurship: Ability, need, and opportunity as determinants of small firm growth. Journal of Business Venturing, 6, 405-429.

Delmar, F. (2006). The psychology of the entrepreneur. In S. Carter \& D. Jones-Evans (Eds.), Enterprise and small business (pp. 152-175). London: Pearson Education.

Demsetz, H. (1982). Barriers to entry. American Economic Review, 72(1), 47-57.

Dixit, A. (1980). The role of investment in entry-deterrence. Economic Journal, 90(357), 95-106.

Dixit, A. K., \& Kyle, A. S. (1985). The use of protection and subsidies for entry promotion and deterrence. American Economic Review, 75(1), 139-152.

Djankov, S., La Porta, R., Lopez-de-Silanes, F., \& Shleifer, A. (2002). The regulation of entry. The Quarterly Journal of Economics, CXVII, 1-37.

Dollinger, M. J. (2003). Entrepreneurship, strategies and resources. Upper Saddle River, New Jersey: Prentice Hall.

Fava, J. L., \& Velicer, W. F. (1996). The effects of underextraction in factor and component analyses. Educational and Psychological Measurement, 56, 907-929.

Gatignon, H., Robbertson, T. S., \& Fein, A. J. (1997). Incumbent defence strategies against new product entry. International Journal of Research in Marketing, 14, 163-176.

Geroski, P. A. (1995). What do we know about entry? International Journal of Industrial Organization, 13, 421-440.

Geroski, P. A., Gilbert, R. J., \& Jacquemin, A. (1990). Barriers to entry and strategic competition, fundamentals of pure and applied economics 41. Chur: Harwood Academic.

Han, J. K., Kim, N., \& Kim, H. B. (2001). Entry barriers: A dull-, one- or two-edged sword for incumbents? Unravelling the paradox from a contingency perspective. Journal of Marketing, 65, January, 1-14.

Harrigan, K. R. (1981). Barriers to entry and competitive strategies. Strategic Management Journal, 2(4), 395-412.

Harrigan, K. R. (1983). Entry barriers in mature manufacturing industries. Advances in Strategic Management, 2, 67-97.

Horn, J. L. (1965). A rationale and test for the number of factors in factor analysis. Psychometrika, 30, 179-186.

Karakaya, F. (2002). Barriers to entry in industrial markets. Journal of Business and Industrial Marketing, 17(5), 379388.

Karakaya, F., \& Stahl, M. J. (1989). Barriers to entry and market entry decisions in consumer and industrial goods markets. Journal of Marketing, 53, 80-91.

Kemp, R. G. M., \& Lutz, C. (2006). Perceived barriers to entry: Are there any differences between small, medium-sized and large companies? International Journal of Entrepreneurship and Small Business, 3(5), 538-553.
Klemperer, P. (1987). Entry deterrence in markets with consumer-switching costs. Economic Journal, 97, 99-117.

Klemperer, P. (1992). Competition when consumers have switching costs: An overview. CEPR Discussion Paper Series 704. London: CEPR

Lieberman, M. B. (1987). Excess capacity as a barrier to entry: An empirical appraisal. Journal of Industrial Economics, 4, 607-627.

Martin, S. (2002). Advanced industrial economics. Malden, MA: Blackwell.

McAfee, R. P., Mialon, H. M., \& Williams, M. A. (2004). What is a barrier to entry? American Economic Review, 94(2), 461-465.

McDermoll, A., Lovatt, S. J., \& Koslow, S. (2004). Supply chain performance measures for producers and processors of premium beef cuts: A conjoint approach. Journal of Chain and Network Science, 44(1), 33-43.

Milgrom, P., \& Roberts, J. (1982). Limit-pricing and entry under incomplete information: An equilibrium analysis. Econometrica, 50(2), 443-460.

Netter, J. M. (1983). Political competition and advertising as a barrier to entry. Southern Economic Journal, 50, October, 510-520.

OECD. (2005). Barriers to entry, DAF/COMP(2005)42. Paris: Directorate for Financial and Enterprise Affairs, Competition Committee.

Porter, M. E. (1980). Competitive strategy. NY: Free.

Porter, M. E. (1985). Competitive advantage: Creating and sustaining superior performance. NY: Free.

Priem, R. L. (1992). An application of metric conjoint analysis for the evaluation of top managers' individual strategic decision making processes: A research note. Strategic Management Journal, 13, 143-151.

Rangone, A. (1999). A resource-based approach to strategy analysis in small-medium sized enterprises. Small Business Economics, 12, 233-248.

Robinson, K. C., \& McDougall, P. P. (2001). Entry barriers and new venture performance: A comparison of universal and contingency approaches. Strategic Management Journal, 22, 659-685.

Scherer, F. M. (1970). Industrial pricing: Theory and evidence. Chicago, IL: Rand McNally College Publishing.

Scherer, F. M. (1988). Review of the economics of market dominance. International Journal of Industrial Organization, 6, 517-519.

Schmalensee, R. (1978). Entry deterrence in the ready-to-eat breakfast cereal industry. The Bell Journal of Economics, 9(2), 305-327.

Schmalensee, R. (1981). Economies of scale and barriers to entry. Journal of Political Economy, 89(6), 1228-1238.

Schmalensee, R. (1982). Product differentiation advantages of pioneering brands. American Economic Review, 72(3), 350-371.

Schmalensee, R. (1983). Advertising and entry deterrence: An exploratory model. Journal of Political Economy, 91(4), 636-653.

Shepherd, D. A. (1999). Venture capitalist' assessment of new venture survival. Management Science, 45(5), 621632.

Shepherd, W. G. (1997). The economics of industrial organisation. Upper Saddle River, NJ: Prentice-Hall International. 
Shepherd, D. A., \& Zacharakis, A. (2000). Structuring family business succession: An analysis of the future leader's decision making. Entrepreneurship: Theory and Practice, 24(4), 25-39.

Shy, O. (2002). A quick-and-easy method for estimating switching costs. International Journal of Industrial Organization, 20, 71-87.

Singh, S., Utton, M., \& Waterson, M. (1998). Strategic behaviour of incumbent firms in the UK. International Journal of Industrial Organization, 16, 229-251.

Smiley, R. (1988). Empirical evidence on strategic entry deterrence. International Journal of Industrial Organization, 6, 167-180.

Spence, A. M. (1977). Entry, capacity, investment and oligopolistic pricing. Bell Journal of Economics, 8(2), 534544.

Spence, A. M. (1980). Notes on advertising, economies of scale and entry barriers. Quarterly Journal of Economics, November, 493-507.

Stigler, G. (1968). The organization of industry. Chicago, IL: University of Chicago Press.
Sutton, J. (1991). Sunk costs and market structure: Price competition, advertising, and the evolution of concentration. Cambridge, MA: MIT Press.

Thomas, L. A. (1999). Incumbent firms' response to entry: Price, advertising and new product introduction. International Journal of Industrial Organization, 17, 527-555.

Van Stel, A., Carree, M., \& Thurik, R. (2005). The effect of entrepreneurial activity on national economic growth. Small Business Economics, 24, 311-321.

Van Stel, A., Storey, D., \& Thurik, R. (2007). The effect of business regulations on nascent and young business entrepreneurship. Small Business Economics, 28, 171-186.

Van Stel, A., Storey, D., Thurik, R., \& Wennekers, S. (2006). From nascent to actual entrepreneurship: The effect of entry barriers. Scales paper N200508, EIM, Zoetermeer.

Von Weizsacker, C. C. (1980). A welfare analysis of barriers to entry. Bell Journal of Economics, 11(2), 399-420.

Wittink, D. R., \& Cattin, P. (1989). Commercial use of conjoint analysis: An update. Journal of Marketing, 53, 91-96.

Yip, G. S. (1982). Barriers to entry: A corporate perspective. Lexicon, MA: Lexicon Books. 